\title{
Knowledge and Attitude Regarding Birth Spacing Methods among Primigravida Mothers Attending Antenatal OPD at a Selected Hospital, Kamrup (M), Assam: A Descriptive Study
}

\author{
Limabenla $^{1}$, Rikynti Nongkynrih ${ }^{2}$ \\ ${ }^{1}$ 2nd Year M.Sc. Nursing, Asian Institute of Nursing Education, Guwahati, Assam, India. \\ ${ }^{2}$ Lecturer, Asian Institute of Nursing Education, Guwahati, Assam, India.
}

Corresponding Author: Limabenla

\begin{abstract}
Introduction: One of the many decisions made in the households, which has consequences on family wellbeing, is the timing and spacing of children. According to WHO birth spacing should be maintained at least two to three years to improve maternal health, reduce infant and child mortality.

Aims \& Objectives: To assess the knowledge and attitude regarding birth spacing methods among primigravida mothers attending antenatal OPD at a selected hospital, Kamrup (M), Assam.

Materials and Methods: A descriptive survey research design was adopted and purposive sampling technique was carried out to collect the samples. The sample size was 100 primigravida mothers who were attending antenatal OPD at Maternity and Child Welfare Hospital, Dhirenpara, Guwahati, Assam and who fulfills the inclusion criteria.

Results: Study findings showed that majority i.e. $48 \%$ respondents have inadequate knowledge, $46 \%$ respondents have moderate knowledge and 6\% have adequate level of knowledge. Also Majority i.e. $78 \%$ respondents have moderately desirable attitude, $22 \%$ have desirable attitude and $0 \%$ had undesirable attitude regarding birth spacing methods. There was moderate positive correlation between knowledge and attitude $(\mathrm{r}=0.309)$. There was significant association of knowledge with education, occupation and pregnancy in months, and also attitude with pregnancy in months, previous information regarding birth spacing and source of information

Conclusion: Study found that knowledge were inadequate with moderately desirable attitude, therefore there should be more awareness programmes related to birth spacing methods among primigravida mothers. So, as to improve their level of knowledge and to have a positive attitude towards birth spacing.
\end{abstract}

Keywords: primigravida, mothers, birth spacing, knowledge, attitude, contraceptive.

\section{INTRODUCTION}

One of the many decisions made in the households, which has consequences on family wellbeing, is the timing and spacing of children. According to WHO birth spacing should be maintained at least two to three years to improve maternal health and to reduce infant and child mortality. ${ }^{[1]}$

Birth spacing has health benefits for both mother and child. Adequate knowledge can promote good practice and help in prevention of risk of complications for mother and child. ${ }^{[2]}$

Not only during reproductive year but also throughout the cause of life, health of the women is an important component. So without having proper constructive involvement, educations and awareness of women, family planning program could never be a successful in Country. ${ }^{[3]}$ 
The greatest health, economical and social benefits for a family is provided by maintaining optimal birth spacing interval. Couples who space their births 3 to 5 years apart have high chances of survival for both the mothers and children's. It also decrease abortions and unwanted pregnancies, improves children's health, nutrition and development, increases equity among community members and helps to preserve the environment. Maintaining birth spacing methods allows the mother to recover physically and psychologically before she can conceive again, and could faces the demands of another pregnancy, birth, child care as well as breast feeding. ${ }^{[4]}$

In India contraceptive needs of young couples especially in the area of spacing pregnancies is mostly unmet. The unmet contraceptive method is directly found to be a reason for short birth Interval. The methods available for birth spacing and knowledge regarding the health benefits of birth spacing are largely unknown. Antenatal period gives a great window of opportunity when the young mothers come in contact with health care providers during which health education can be provided regarding the need, methods as well as benefits available for birth spacing. ${ }^{[5]}$

An interval between the last live birth and the next pregnancy of at least 24 months, a birth interval of 33 months has being currently recommends by WHO (2020). Around 2 million of the 11 million deaths per year of children under 5 years of age could be prevented by avoiding birth intervals of less than 2 years as one of the estimate suggests. To address for short birth interval international bodies like WHO and USAID have called for further research and actions. Women belong to low and middle income countries are more common to have short birth interval, an estimated $17 \%$ of married women of reproductive age was reported to have unmet needs for family planning. For example, 2018 Nigerian Demographic and Health Survey (DHS), have reported that $19 \%$ of married women have unmet family planning needs.
Similarly 2013 Nigerian Demographic and Health Survey (DHS), have found that 23\% of women had birth interval less than 24 months, for their last two births and 62\% had birth interval less than 36 months. ${ }^{[6]}$

Ashok Y and Koshalya (2017) conducted a study on Knowledge and attitude among antenatal mothers regarding postpartum intrauterine contraceptive devices (PPIUCD) at a selected hospital of Jaipur district. A descriptive survey approach was used for the study, a sample of 70 antenatal mothers was chosen by systematic sampling technique, a structured knowledge questionnaire was developed to assess the knowledge \& its reliability was established. To assess the attitude of antenatal mothers towards PPIUCD, 5 point Likert scale was developed. The study finding shows that majority i.e. $81.4 \%$ of the antenatal mothers, had poor knowledge regarding PPIUCD. It also shows that 50\% of the antenatal mothers, had favourable attitude towards PPIUCD. There was a significant positive relationship between knowledge and attitude $(\mathrm{r}=.749)$ at 0.05 level of significance. To improve the knowledge and favourable attitude of the mothers regarding PPIUCD, the nurse as well as health care providers should play a significant role in educating the mothers. ${ }^{[7]}$

The investigator during her clinical posting came across with many pregnant mothers with poor knowledge about birth spacing methods and also practices of less birth interval, and they were not aware about the risk for both mother and child. Based on investigator's experience and after reviewing above facts, the investigator feels that it is very important to create awareness among the primigravida mothers regarding birth spacing methods so that to provide adequate knowledge and awareness to promote the health status by practicing the birth spacing methods.

\section{Objectives of the study}

1. To assess the level of knowledge regarding birth spacing methods among primigravida mothers. 
Limabenla et.al. Knowledge and attitude regarding birth spacing methods among primigravida mothers attending antenatal OPD at a selected hospital, Kamrup (M), Assam: a descriptive study.

2. To assess the attitude regarding birth spacing methods among primigravida mothers.

3. To find out the co-relation between the level of knowledge and attitude regarding birth spacing methods among primigravida mothers.

4. To find the association between the knowledge and attitude regarding birth spacing methods with the selected demographic variables.

\section{METHODS}

Descriptive survey research design was used to conduct the study among primigravida mothers attending antenatal OPD at Maternity and Child Welfare Hospital, Dhirenpara, Guwahati, Assam.100 primigravida were selected by using purposive sampling technique. The samples included in this study were Primigravida mothers who were present in a selected hospital during the time of data collection and Primigravida mothers who were willing to participate. Semi structured questionnaire and Self structured 5 point Likert scale was used to assess the knowledge and attitude regarding birth spacing methods. Ethical permission was obtained before the data collection process and after obtaining permission from the setting primigravida mothers were asked for their willingness to participate in the study, and informed consent was obtained. After collecting demographic data, the semi structured knowledge questionnaire and self structured 5 point Likert scale regarding birth spacing methods was administered. Analyzing of the collected data was done by using descriptive and inferential statistics.

\section{Description of the tool}

The tools used for the study consisted of three (3) sections:

Section I: Demographic data of the primigravida mothers.

Section II: Semi structured knowledge questionnaire regarding birth spacing methods.

Section III: Self structured 5 points Likert scale to assess attitude.

\section{RESULTS}

Table I: Frequency and Percentage Distribution of primigravida mothers According to Demographic Variables. $\mathbf{n}=\mathbf{1 0 0}$

\begin{tabular}{|c|c|c|c|}
\hline \multicolumn{2}{|l|}{ VARIABLES } & \multirow{2}{*}{$\begin{array}{l}\text { (F) } \\
60\end{array}$} & \multirow{2}{*}{$\frac{(\%)}{60}$} \\
\hline Age in years & $\leq 25$ & & \\
\hline & $26-35$ & 35 & 35 \\
\hline & $>35$ & 5 & 5 \\
\hline \multirow[t]{4}{*}{ Religion } & Hindu & 63 & 63 \\
\hline & Muslim & 37 & 37 \\
\hline & Christian & - & - \\
\hline & Others & - & - \\
\hline \multirow[t]{4}{*}{ Education } & Primary school & 23 & 23 \\
\hline & High school & 37 & 37 \\
\hline & Secondary education & 25 & 25 \\
\hline & Graduate and above & 15 & 15 \\
\hline \multirow[t]{4}{*}{ Occupation } & Business & 22 & 22 \\
\hline & Private employee & 14 & 14 \\
\hline & Government. Servant & 7 & 7 \\
\hline & Others & 57 & 57 \\
\hline \multirow[t]{3}{*}{ Type of family } & Nuclear family & 53 & 53 \\
\hline & Joint family & 47 & 47 \\
\hline & Extended family & - & - \\
\hline \multirow[t]{3}{*}{ Pregnancy in months } & $\leq 3$ months & 37 & 37 \\
\hline & $4-6$ months & 24 & 24 \\
\hline & $\geq 7$ months & 39 & 39 \\
\hline \multirow{2}{*}{$\begin{array}{l}\text { Previous information } \\
\text { regarding birth spacing }\end{array}$} & Yes & 78 & 78 \\
\hline & No & 22 & 22 \\
\hline \multirow[t]{5}{*}{ Source of information } & Health Professionals & 38 & 38 \\
\hline & $\begin{array}{l}\text { Mass media (TV, } \\
\text { Radio, Internet) }\end{array}$ & 15 & 15 \\
\hline & Friends and Relatives & 19 & 19 \\
\hline & Others & 6 & 6 \\
\hline & No. & 22 & 22 \\
\hline
\end{tabular}

Table II: Frequency and Percentage Distribution of primigravida mothers According to the Level of Knowledge, $n=100$

\begin{tabular}{|c|c|c|c|c|c|c|}
\hline Level of knowledge & Frequency & Percentage & Mean & SD & Range of score & Total score \\
\hline Inadequate $(\leq 8$ score $) \leq 33 \%$ & 48 & 48 & \multirow{3}{*}{9 , с .35} & \multirow{3}{*}{4.12} & \multirow{3}{*}{$3-20$} & \multirow{3}{*}{24} \\
\hline Moderate $(9-16$ score) $34 \%-66 \%$ & 46 & 46 & & & & \\
\hline Adequate $(\geq 17$ score $) \geq 67 \%$ & 6 & 6 & & & & \\
\hline
\end{tabular}

The data represented in Table II depicts that out of 100 primigravida mothers majority that is $48(48 \%)$ had inadequate knowledge, $46(46 \%)$ had moderately adequate knowledge and only six $(6 \%)$ had adequate knowledge regarding birth spacing methods among primigravida mothers. The overall mean is 9.35 and SD of knowledge level is 4.12 respectively. 
Limabenla et.al. Knowledge and attitude regarding birth spacing methods among primigravida mothers attending antenatal OPD at a selected hospital, Kamrup (M), Assam: a descriptive study.

Table III: Frequency and Percentage Distribution of primigravida mothers According to the Level of Attitude, $n=100$

\begin{tabular}{|l|l|l|l|l|l|l|}
\hline Level of attitude & Frequency & Percentage & Mean & SD & Range of score & Total score \\
\hline Undesirable $(\leq 23$ score $) \leq 33 \%$ & 0 & 0 & 42.11 & 7.09 & $28-60$ & 70 \\
\cline { 1 - 3 } Moderately desirable $(24-46$ score) $34 \%-66 \%$ & 78 & 78 & & & & \\
\cline { 1 - 3 } Desirable $(\geq 47$ score $) \geq 67 \%$ & 22 & 22 & & & & \\
\hline
\end{tabular}

The data represented in Table III depicts that out of 100 primigravida mothers majority of the respondents that is $78(78 \%)$ had moderately desirable attitude, 22 (22\%) had desirable attitude and none of the respondents had undesirable attitude regarding birth spacing methods among primigravida mothers. The overall mean is 42.11 and SD of attitude level is 7.09 respectively.

Table III: Association of level of knowledge regarding birth spacing methods among primigravida mothers with selected demographic variables. $n=100$

\begin{tabular}{|l|l|l|l|l|l|}
\hline Variable & Level of significance & Chi square & df & p-value & Remarks \\
\hline Age in years & 0.05 & 2.577 & 4 & 0.655 & Not significant as $\mathrm{p}>0.05$ \\
\hline Religion & 0.05 & 2.993 & 2 & 0.221 & Not significant as p $>0.05$ \\
\hline Education & 0.05 & 52.060 & 6 & 0.0001 & Significant at $\mathrm{p}<0.001$ \\
\hline Occupation & 0.05 & 28.642 & 6 & 0.0001 & Significant at $\mathrm{p}<0.001$ \\
\hline Type of family & 0.05 & 2.580 & 2 & 0.259 & Not significant as $\mathrm{p}>0.05$ \\
\hline Pregnancy in months & 0.05 & 10.085 & 4 & 0.026 & Significant at $\mathrm{p}<0.05$ \\
\hline Previous information regarding birth spacing & 0.05 & 3.093 & 2 & 0.199 & Not significant as p $>0.05$ \\
\hline Source of information & 0.05 & 6.949 & 8 & 0.502 & Not significant as p $>0.05$ \\
\hline
\end{tabular}

The data presented in the above Table III depicts that demographic variables such as education and occupation had shown statistically significant association with level of knowledge regarding birth spacing methods among primigravida mothers at $\mathrm{p}<0.001$ and pregnancy in months at $\mathrm{p}<0.05$, and no association with other demographic characteristics such as age, religion, type of family, previous information regarding birth spacing and source of information.

Table IV: Association of level of attitude regarding birth spacing methods among primigravida mothers with selected demographic variables. $\mathbf{n}=\mathbf{1 0 0}$

\begin{tabular}{|l|l|l|l|l|l|}
\hline Variable & Level of significance & Chi square & df & p-value & Remarks \\
\hline Age in years & 0.05 & 3.070 & 2 & 0.204 & Not significant as $\mathrm{p}>0.05$ \\
\hline Religion & 0.05 & 0.005 & 1 & 1.000 & Not significant as $\mathrm{p}>0.05$ \\
\hline Education & 0.05 & 3.698 & 3 & 0.292 & Not significant as $\mathrm{p}>0.05$ \\
\hline Occupation & 0.05 & 5.593 & 3 & 0.119 & Not significant as $\mathrm{p}>0.05$ \\
\hline Type of family & 0.05 & 0.027 & 1 & 1.000 & Not significant as $\mathrm{p}>0.05$ \\
\hline Pregnancy in months & 0.05 & 6.625 & 2 & 0.038 & Significant at $\mathrm{p}<0.05$ \\
\hline Previous information regarding birth spacing & 0.05 & 7.955 & 1 & 0.003 & Significant at $\mathrm{p}<0.01$ \\
\hline Source of information & 0.05 & 11.818 & 4 & 0.013 & Significant at $\mathrm{p}<0.05$ \\
\hline
\end{tabular}

The data presented in the above Table IV depicts that demographic variables such as previous information regarding birth spacing had shown statistically significant association with level of attitude regarding birth spacing among primigravida mothers at $p<0.01$, pregnancy in months and source of information at $p<0.05$ and no association with other demographic characteristics such as age, religion, education occupation and type of family.

Table V: correlation between knowledge and attitude
regarding birth spacing methods among primigravida
mothers. n=100 \begin{tabular}{|l|l|l|l|l|}
\hline Variables & Mean & SD & 'r' value & 'p' value \\
\hline Knowledge & 9.35 & 4.12 & 0.309 & $0.002, S^{* *}$ \\
\hline Attitude & 42.11 & 7.09 & & \\
\hline
\end{tabular}

Data from table reveals that the ' $r$ ' value is 0.309 and ' $p$ ' value is 0.002 which is significant at $p<0.001$ level of significant. There is a moderate positive correlation between knowledge and attitude level regarding birth spacing methods among primigravida mothers. It clearly infers that as the level of knowledge were inadequate, there were moderately desirable attitude.

\section{DISCUSSION}

The finding of the study revealed that out of 100 primigravida mothers majority i.e. $48 \%$ of the primigravida mothers have inadequate knowledge $46 \%$ of the respondents have moderate knowledge 
and $6 \%$ have adequate knowledge regarding birth spacing methods among primigravida mothers. Ashok Y and Koshalya conducted a descriptive survey approach on Knowledge and attitude among antenatal mothers regarding postpartum intrauterine contraceptive devices (PPIUCD) at a selected hospital of Jaipur district, which revealed majority $81.4 \%$ of the antenatal mothers, had poor knowledge regarding PPIUCD and only $18.6 \%$ had good knowledge. The result which is in accord with our study finding. ${ }^{[7]}$

The finding of the study revealed that out of 100 primigravida mothers majority i.e. $78 \%$ of the primigravida mothers have moderately desirable attitude, $22 \%$ have desirable attitude and $0 \%$ had undesirable attitude regarding birth spacing methods among primigravida mothers. Lincoln J, Mohammadnezhad M and Khan $\mathrm{S}$, conducted a quantitative cross-sectional study on Knowledge, Attitudes, and Practices of Family Planning among Women of Reproductive Age in Suva, Fiji, which revealed that majority of the respondents i.e. $54.2 \%$ had high level of attitudes towards family planning, whereas only 3\% of the respondents showed poor level of attitude towards family planning. The result which is in contrast with our study finding. ${ }^{[8]}$

The present study depicts that demographic variables such as education and occupation had shown statistically significant association with level of knowledge regarding birth spacing methods among primigravida mothers at $p<0.001$ and pregnancy in months at $\mathrm{p}<0.05$, and no association with other demographic characteristics such as age, religion, type of family, previous information regarding birth spacing and source of information. It also shows that demographic variables such as previous information regarding birth spacing had shown statistically significant association with level of attitude regarding birth spacing among primigravida mothers at $p<0.01$, pregnancy in months and source of information at $p<0.05$ and no association with other demographic characteristics such as age, religion, education occupation and type of family.

The present study reveals that the ' $r$ ' value is 0.309 and ' $p$ ' value is 0.002 which is significant at $p<0.001$ level of significant. There is a moderate positive correlation between knowledge and attitude level regarding birth spacing methods among primigravida mothers. It clearly infers that as the level of knowledge were inadequate, there were moderately desirable attitude.

\section{CONCLUSION AND RECOMMENDATIONS}

Through this study, the investigator concluded although the knowledge were inadequate but there was moderately desirable attitude regarding birth spacing methods among primigravida mothers. After this study, it is recommended that there should be more awareness programmes related to birth spacing methods among primigravida mothers including the family members to improve their knowledge, attitude as well as practice towards family planning. The health care worker should also take an active participation in educating the patient and their family members about the family planning methods and risk of short spacing by giving up to date information which in turn will help in reduction of infant and maternal mortality rate.

Acknowledgement: None

\section{Conflict of Interest: None}

\section{Source of Funding: None}

\section{REFERENCES}

1. Nti CA, Gadegbeku C, Dodoo SNA, et al. Knowledge, Attitude and Practice of Birth Spacing among Ghanaian Mothers: Implications for Maternal and Child Nutritional Status. WASJ, 2014 January: 31(11)1971-1978[cited on 2021 Feb 7] Available from: URL: https://www.researchgate.net/publication/33 2902538. 
Limabenla et.al. Knowledge and attitude regarding birth spacing methods among primigravida mothers attending antenatal OPD at a selected hospital, Kamrup (M), Assam: a descriptive study.

2. Park K. Park's textbook of preventive and social medicine. $23^{\text {rd }}$ ed. Jabalpur. M/s Banarsidas Bhanot; 2015.

3. Priyadharshini $\mathrm{S}$ and Dash $\mathrm{M}$. A study on to assess the knowledge and attitude regarding importance birth spacing methods among primi postnatal mothers in postnatal ward at Rajiv Gandhi Government Women and Children Hospital Puducherry, India. IRJMS, 2016 August; 4(9): 1-4. [Cited on 2021 Feb 18] Available from: URL: http://www.isca.in/MEDI_SCI/Archive/v4/i 9/1.ISCA-IRJMedS-2016-009.pdf.

4. Elida FL, Mahakalkar M. To Assess the Knowledge Regarding Importance of Birth Spacing among Post Natal Primi Mothers in the Selected Hospitals. IJSR, 2017 Sep; 6 (9) 433-435 [cited on 2021 Feb 7] Available from:

URL: https://www.ijsr.net/archive/v6i9/ART2017 6559.pdf.

5. Rajan V and Kandasamy S. A study on Awareness regarding birth spacing family planning methods among antenatal mothers. IJRCOG, 2021 January; 10(1): 93-96 [Cited on 2021 March 31] Available from: URL: file:///C:/Users/Acer/Downloads/949833544-2-PB.pdf.

6. Pimentel J, Ansari U, Omer $\mathrm{K}$, et al. Factors associated with short birth interval in low and middle income countries: a systematic review. BMC Pregnancy and Childbirth, 2020 March; 20:156 [cited on 2021 Feb7] Available from: URL: https://bmcpregnancychildbirth.biomedcentr al.com/articles/10.1186/s12884-020-2852-z.

7. Ashok $Y$ and Koshalya. A study on Knowledge and attitude among antenatal mothers regarding PPIUCD at a selected hospital of Jaipur district. IJMHR, 2017 November; 3(11): 63-65. [Cited on 2021 Feb 18] Available from: URL: file://C:/Users/Acer/Downloads/3-11-12147.pdf.

8. Lincoln J, Mohammadnezhad M and Khan S. A study on Knowledge, Attitudes, and Practices of Family Planning among Women of Reproductive Age in Suva, Fiji. JWHC, 2018 May; 7(3): 1-6. [Cited on 2021 Feb 18] Available from: URL: https://www.longdom.org/open-access.

How to cite this article: Limabenla, Nongkynrih R. Knowledge and attitude regarding birth spacing methods among primigravida mothers attending antenatal OPD at a selected hospital, Kamrup (M), Assam: a descriptive study. Int $J$ Health Sci Res. 2021; 11(9): 197-202. DOI: https://doi.org/10.52403/ijhsr.20210931 